\title{
Fine motor analysis of infants aged 7-12 months based on breast milk
}

\author{
Indah Rahmadaniah $^{1^{*}}$, Marchatus Soleha ${ }^{2}$, Rini Anggeriani $^{3}$ \\ ${ }^{1,3}$ DIII Midwifery Study Program STIKES Abdurahman Palembang, Indonesia \\ ${ }^{2}$ S1 Midwifery Study Program STIKES Abdurahman Palembang, Indonesia \\ 1indahdaniah16@gmail.com*; ${ }^{2}$ marchatussoleha14@gmail.com; ${ }^{3}$ anggeriani_r@ymail.com \\ *corresponding author \\ Submission date: 21 April 2021, Receipt date: 16 Mei 2021, Publication date: 1 Juli 2021
}

\begin{abstract}
This study aims to produce new scientific information about the fine motor skills of breastfed infants. Method: The type of research is an analytic survey. The population, all infants aged 7-12 months as many as 57 babies, the sample was taken by purposive sampling as many as 47 respondents, the data was taken through a survey using Google forms. Data analysis using chi-square statistical test. Result: obtained p-value =0,058. In conclusion, there is no significant relationship between breastfeeding and fine motor skills in infants aged 7-12 months.
\end{abstract}

Keywords: fine motor, a baby aged 7-12 months, breastfeeding

\section{INTRODUCTION}

Breast milk is the best food for babies, this is already widely known by everyone, the amount of information that has been given by various parties ranging from the government, health workers, associations, breastfeeding support movements and many others, makes mothers can easily find out information about breastfeeding, besides that there are also many efforts made to increase exclusive breastfeeding to babies by providing counseling, training on breast care and good breastfeeding methods so that mothers can optimally provide exclusive breastfeeding to their babies (Karang et al., 2020). The Government Regulation of the Republic of Indonesia in PP no.33 of 2012 concerning Exclusive Breastfeeding requires every mother who gives birth to give exclusive breastfeeding to babies born up to 6 months without adding and/or replacing with food or drink.

Many phenomena occur in the process of breastfeeding infants, this can be seen from the number of breastfeeding mothers who cannot give their breast milk to their babies due to various factors, one of which is the baby's factors such as the inability to receive breast milk (congenital disorders), breastfeeding initiation is not carried out. early delivery, time not fully with the baby, mammary gland development, and inadequate secretion of the hormones prolactin and oxytocin (Karang et al., 2020).

The child's growth period is an important period in every step to achieve optimal growth and development, WHO/UNICEF recommends four important things that must be done, namely firstly giving breast milk to the baby immediately within 30 minutes 
after the baby is born, secondly giving only breast milk or exclusive breastfeeding from birth until the baby is 6 months old, the third provides complementary feeding (MP-ASI) from the baby aged 6 months to 24 months and the fourth continues breastfeeding until the child is 24 months old or older (Kemenkes, 2019).

According to Aisyah, (2017) babies who are exclusively breastfed experience faster growth and development and have good nutritional status so that babies can perform both gross and fine motor skills. Growth and development are two distinct but interrelated events. Growth is related to changes in size, number, length, bone age, and metabolic balance, while development is an increase in abilities in more complex body structures and functions in a regular and predictable pattern, as a result of the maturation process (Mualifah \& Punjastuti, 2019).

Research result Desitawati et al., (2020) It is known from 18 infants who received exclusive breastfeeding, as many as 14 infants (78\%) had normal fine motor skills and 4 infants $(22 \%)$ had abnormal fine motor skills, while from 18 infants who received exclusive breastfeeding, there were 12 infants (67\%) who had motor skills. normal gross motor skills, 6 babies (33\%) with abnormal gross motor skills, according to his research several factors influence the development of fine motor and gross motor skills, the main factor is nutrition, where babies who are exclusively breastfed will have better development, babies who get Exclusive breastfeeding will get a good nutritional status so that in carrying out motor development activities the baby can do well.

Fine motion or fine motor skills are aspects related to the child's ability to perform movements that involve certain body parts and are carried out by small muscles, but require careful coordination such as observing something, pinching, writing, and so on (Kementrian Kesehatan, 2016).

Other studies have shown that there is no effect of exclusive breastfeeding on the level of child development with a $p$-value obtained at a growth rate of $p=0.070>0.05$ and a correlation coefficient range with a value of $r=0.199$, which means it is very small and can be ignored. Exclusive breastfeeding on the child's growth rate (Tianingsih, 2020).

The results of the research conducted by Zaid found that 15 infants were exclusively breastfed with appropriate infant development as much as $66.6 \%$, dubious infant development $26.7 \%$, and infant development having deviations of $6.6 \%$, many factors can affect development ranging from heredity to environmental factors, so for babies aged 6 months who have dubious development are expected to be given stimulation, babies aged 6 months who are exclusively breastfed also have the possibility of deviations, babies who experience deviations do not mean they can't do anything, but babies who have not achieved development according to their age (Zaid et al., 2016).

The growth and development of infants aged 7-12 months really need good nutritional intake, therefore at this time babies should be given the best food, namely breast milk, there have been many studies that prove that breast milk is the best and can help the baby's growth and development well, however, this research was conducted to produce new theories/scientific information about the fine motor skills of breastfed infants. 


\section{RESEARCH METHODS}

This research is a descriptive-analytic study using a cross-sectional approach. The population in this study were all infants aged 7-12 as many as 57 respondents. The sampling technique used purposive sampling technique with inclusion criteria, namely healthy infants aged 7-12 months, parents willing to be respondents, and exclusion criteria were babies born prematurely, babies with congenital abnormalities so that the number of samples was 47 respondents. This research was conducted in March-May 2020 at BPM Fauziah Hatta Palembang.

The data used are primary data obtained from the survey results, to assess the fine motor development of infants used Pre-screening Development Questionnaire (KPSP) which is contained in the google form. The data analysis technique used univariate and bivariate analysis using the chi-square statistical test with a significance limit of $=0.05$.

\section{RESULTS AND DISCUSSION}

\section{Characteristics of Respondents}

In this study, the characteristics of the respondents were based on age, gender, education, occupation, and children. The results of the study can be seen in the table below:

Table 1. Frequency Distribution Based on Characteristics of Respondents

\begin{tabular}{|c|c|c|c|c|}
\hline \multirow{2}{*}{ No } & \multirow{2}{*}{\multicolumn{2}{|c|}{ Characteristics }} & \multicolumn{2}{|c|}{ Amount } \\
\hline & & & Frequency & Percentage (\%) \\
\hline \multirow[t]{4}{*}{1.} & Baby age & $7-8$ months & 32 & 68.1 \\
\hline & & 9-10 months & 6 & 12.8 \\
\hline & & 11-12 months & 9 & 19.1 \\
\hline & Amount & & 47 & 100 \\
\hline \multirow[t]{3}{*}{2.} & Gender & Man & 25 & 53.2 \\
\hline & & Woman & 22 & 46.8 \\
\hline & Amount & & 47 & 100 \\
\hline \multirow[t]{5}{*}{3.} & Childs number & 1 & 14 & 29.8 \\
\hline & & 2 & 19 & 40.4 \\
\hline & & 3 & 9 & 19.1 \\
\hline & & 4 & 5 & 10.6 \\
\hline & Amount & & 47 & 100 \\
\hline \multirow[t]{5}{*}{4.} & Mother's & SD & 3 & 6.4 \\
\hline & Education & Junior high school & 10 & 21.3 \\
\hline & & Senior High School & 28 & 59.5 \\
\hline & & PT & 6 & 12.8 \\
\hline & Amount & & 47 & 100 \\
\hline \multirow[t]{5}{*}{5.} & Mother's Job & ART & 32 & 68.1 \\
\hline & & Entrepreneur & 7 & 14.9 \\
\hline & & Private & 5 & 10.6 \\
\hline & & Etc & 3 & 6.4 \\
\hline & Amount & & 47 & 100 \\
\hline
\end{tabular}

Based on table 1. above, it can be seen from the survey results using google form that the characteristics of respondents based on the age of the baby, from 47 respondents, most of the babies aged 7-8 months, namely 32 respondents $(68.1 \%)$, respondents aged 9-10 months as many as 6 respondents (12.8\%) and aged 11-12 months as many as 9 respondents $(19.1 \%)$. Characteristics of respondents by gender, from 47 respondents, 
most of 25 respondents $(53.2 \%)$ were male and 22 respondents $(46.8 \%)$ were female. Characteristics of respondents based on the child to, it is known from 47 respondents, there are 14 respondents $(29.8 \%)$ child to 1,19 respondents $(40.4 \%)$ child to 2,9 respondents $(19.1 \%)$ child to 3 , and 5 respondents $(10.6 \%) 4$ th child. Characteristics of respondents based on education are known from 47 respondents, there are 3 respondents $(6.4 \%)$ with elementary education, 10 respondents $(21.3 \%)$ with junior high school education, 28 respondents $(59.5 \%)$ with high school education, and 6 respondents $(12.8 \%)$ with tertiary education. The characteristics of respondents based on occupation from table 1 are known from 47 respondents, there are 32 respondents (68.1\%) as housewives (IRT), 7 respondents $(14.9 \%)$ work as entrepreneurs, 5 respondents $(10.6 \%)$ work in private and 3 respondents $(6.4 \%)$ work in other jobs.

\section{Breastfeeding}

The results of the research on breastfeeding are divided into 2 categories, namely 1. Exclusive breastfeeding 2. Not exclusive breastfeeding. The results of the research can be seen in the table below:

Table 2. Distribution of Breastfeeding Frequency

\begin{tabular}{ccc}
\hline Breastfeeding & Frequency & \% \\
\hline Exclusive breastfeeding & 33 & 70.2 \\
Not Exclusive Breastfeeding & 14 & 29.8 \\
\hline Total & 47 & 100 \\
\hline
\end{tabular}

Based on table 2 above, it can be seen that of the 47 respondents, 33 respondents (70.2\%) were given exclusive breastfeeding, while 14 respondents $(29.8 \%)$ were not given exclusive breastfeeding.

In this study, it was found that the majority of infants had been exclusively breastfed as much as $70 \%$, this percentage was not much different from the percentage of infants who received exclusive breastfeeding in the city of Palembang in 2020 which was $76.1 \%$ (Dinas Kesehatan Kota Palembang, 2020). The coverage of exclusive breastfeeding at BPM Fauziah Hatta and in the city of Palembang is still far from the coverage target in Indonesia, which is based on Government Regulations33 of 2012 article 6, the achievement target for exclusive breastfeeding in Indonesia is $100 \%$.

On World Breastfeeding Week, Kemenkes, (2019), recommending exclusive breastfeeding for 6 months, and continuing optimal breastfeeding until the age of 2 years is an absolute must to improve baby's health. The number of babies who have been exclusively breastfed in this study is in line with the results of research conducted by Yanti (2017), namely the percentage of babies who are exclusively breastfed as much as $81.3 \%$, according to him the number of mothers who give exclusive breastfeeding to their babies is influenced by the mother's work, where most of the mothers work as housewives so that mothers are free to give breast milk to their children because mothers do not work outside the home. Same with the research results Maria et al., (2020), it is known that as many as $56.5 \%$ of respondents received exclusive breastfeeding at the Pandanaran Health Center Semarang, the coverage of exclusive breastfeeding at the Pandanaran Health Center is less than the coverage of the health profile of Central Java Province in 2014, from the results of the study it is known that the reason why babies are not exclusively breastfed is that breastfeeding is not smooth and the mother works outside the home. 
From the results of this study, it is known that as many as $29.8 \%$ of infants who are not exclusively breastfed by their mothers for various reasons such as working mothers so they cannot give their milk, mothers feel that their milk is lacking so they add formula milk, mothers who from the beginning do not give breast milk because their nipples sink. This research is in line with researchNurlaila, Kholifah, and Ning (2017), which states that Most of the non-exclusively breastfed babies come from mothers with the status of working mothers/career mothers. Azhari's research also states that some mothers cannot provide breast milk to their children due to several factors, namely, mothers work outside the home, mothers cannot produce breast milk because of the mother's physical condition that is not supportive, the psychological level or attitude of the mother such as the mother is stressed, the baby's reflexes when breastfeeding. and families who support mothers in the breastfeeding process (Azhari, 2019).

Exclusive breastfeeding for infants has met the needs of good nutrition in infants so that children can grow with optimal development, the family is the closest person to the mother who can support the mother in giving her breast milk to the baby, the role of the family is very important for the mother's success in providing breastfeeding. Exclusive breastfeeding, besides that the government has also supported exclusive breastfeeding for babies by making breastfeeding corners/breastfeeding rooms in public places, providing lactation counseling, and also various movements to support breastfeeding.

\section{Fine Motor Development}

The results of data analysis of the frequency distribution of fine motor development in infants aged 7-12 months were divided into 3 categories, namely 1. Appropriate 2. Doubtful 3. Deviation. The results of the study can be seen in the table below:

Table 3. Frequency Distribution of Fine Motor Development

\begin{tabular}{lcc}
\hline \multicolumn{1}{c}{ Fine Motor Development } & Frequency & \% \\
\hline In accordance & 39 & 83.0 \\
Doubtful & 7 & 14.9 \\
Deviation & 1 & 2.1 \\
\hline Total & 47 & 100 \\
\hline
\end{tabular}

Based on table 3 above, it can be seen that from 47 respondents, there are 39 respondents $(83 \%)$ whose fine motor skills are appropriate, while 7 respondents $(14.9 \%)$ have doubtful fine motor skills, said to be doubtful, this is suspected to have developmental delays and there is 1 respondent $(2,1 \%)$ with deviant fine motor development.

In this study, most of the respondents $83 \%$ have appropriate fine motor skills, appropriate child development can be supported by parents who have good knowledge about how to stimulate their children this can be influenced by the mother's education, occupation, and several children owned, the higher the mother's education the better the mother in absorbing knowledge, the mother who does not work has the most time to always be with her child so that the mother can fully understand the child, the number of children that the mother has is the mother's priority in caring for her child optimally. 
The results of this study are in line with the research of Desitawati et al., (2020) is Of the 18 infants who received exclusive breastfeeding, 14 infants (78\%) had normal fine motor skills and 12 infants $(67 \%)$ had normal gross motor skills., according to desitawati several factors affect the development of fine motor and gross motor, the main factor is nutrition, where babies who are exclusively breastfed will have better development, babies who are exclusively breastfed will get good nutritional status so that in carrying out motor development activities babies can do well. Study Yanti (2017), stated that the appropriate fine motor development is influenced by the age of the mother who is mature in thinking so that the mother can properly filter information about the stimulation of her child's fine motor development, a small number of children (2-3) makes it easier for mothers to give more attention to their children so that Mothers can stimulate their children's fine motor skills by playing together.

In this study, there were infants with doubtful fine motor skills $14.9 \%$ and infants with deviant fine motor skills $2.1 \%$ this was due to the possibility of many factors that could influence it such as family, age, gender, heredity, nutrition, and comorbidities. This is following the theory according to Kementrian Kesehatan (2016), the factors that affect the growth and development of children are race, family, age, gender, genetics, maternal nutrition, childbirth complications, infant nutrition, chronic diseases, environment, child psychology, parenting, stimulation, and drugs.

According to research results Nurlaila, Kholifah, and Ning (2017), many factors can inhibit or stimulate fine motor development in infants and toddlers. Nutrition from breast milk is one of the factors that affect the process of child growth and development, especially on fine motor development. In addition to these factors, environmental factors and stimulation are also important for a baby's fine motor development, one of which is by doing baby massage and spa.

\section{Relationship Between Breastfeeding and Fine Motor Development}

To find out the relationship between breastfeeding and the fine motor development of infants aged 6-12 months, the chi-square test (X2) was used, with a significance level $(\alpha)=0.05$ and a $95 \%$ confidence level (CL). with a limit of significance, $<0.05$, if the value of $\mathrm{p}<$, it means that there is a significant (significant) relationship and if the value of $p>$ means that there is no significant relationship. The results of the chisquare statistical test can be seen in Table 4 below:

Table 4. Relationship Between Breastfeeding and Fine Motor Development

\begin{tabular}{|c|c|c|c|c|c|c|c|c|c|}
\hline \multirow[t]{3}{*}{ Breastfeeding } & \multicolumn{6}{|c|}{ Fine Motor Development } & \multirow{2}{*}{\multicolumn{2}{|c|}{ Total }} & \multirow{3}{*}{$\begin{array}{c}\text { P- } \\
\text { Value }\end{array}$} \\
\hline & \multicolumn{2}{|c|}{$\begin{array}{c}\text { In } \\
\text { accordance }\end{array}$} & \multicolumn{2}{|c|}{ Doubtful } & \multicolumn{2}{|c|}{ Deviation } & & & \\
\hline & $\mathbf{n}$ & $\%$ & $\mathbf{n}$ & $\%$ & $\mathbf{n}$ & $\%$ & $\mathbf{n}$ & $\%$ & \\
\hline Exclusive breastfeeding & 30 & 63.8 & 3 & 6.4 & 0 & 0 & 33 & 70.2 & \\
\hline Not exclusive breastfeeding & 9 & 19.1 & 4 & 8.5 & 1 & 2.1 & 14 & 29.8 & 0.058 \\
\hline Total & 39 & 83.0 & 7 & 14.9 & 1 & 2.1 & 47 & 100 & \\
\hline
\end{tabular}

Based on table 4 above, it can be seen that from 33 respondents who were given exclusive breastfeeding, 30 respondents $(63.8 \%)$ had appropriate fine motor development, while there were 3 respondents $(6.4 \%)$ who doubted and none experienced deviations. From table 4 above, it is also known that of the 14 respondents who were not given exclusive breastfeeding, there were 9 respondents $(19.1 \%)$ whose fine motor 
development was appropriate, while 4 respondents $(8.5 \%)$ doubted and 1 respondent experienced deviations $(2.1 \%)$.

Statistical test results chi-square obtained $\mathrm{p}$-value $=0,058$, this means $\mathrm{p}$-value $>$ 0.05 , which means there is no significant relationship between breastfeeding and fine motor skills in infants 7-12 months.

The results of this study are not in line with research results Nurlaila, Kholifah, and Ning (2017), research by using a non-parametric chi-square test showed that there was a significant relationship between exclusive breastfeeding and fine motor development in infants aged 6-18 months with a p-value of 0.000. According to him, exclusive breastfeeding can affect development because breast milk has good content for child development, breastfeeding can also be stimulation for child development.

The research of Utami et al., (2018) showed that infants who were exclusively breastfed had a 9.9 times greater chance of experiencing appropriate motor development than infants who were not exclusively breastfed, there was a positive and statistically significant relationship $(\mathrm{p}<0.001 ; \mathrm{OR}=9.88 ; 95 \% \mathrm{CI}=3.05-31.97)$. Exclusive breastfeeding has a positive and statistically significant relationship with infant motor development because exclusive breastfeeding contains various nutrients that play an important role in the growth and development of the baby's brain.

Several studies have shown a relationship between breastfeeding and fine motor skills in infants, but this study showed different results, the results showed that there was no relationship between breastfeeding and infant fine motor skills. There are $19.1 \%$ of infants who are not exclusively breastfed but whose fine motor skills are appropriate and there are $6.4 \%$ of infants who were exclusively breastfed with doubtful fine motor skills were suspected of having delays, this could be due to other factors that were not controlled in this study.

The baby's fine motor development can be influenced by many factors, including race, family, age, gender, genetics, nutrition, disease, environment, psychological, socioeconomic, stimulation, drugs, and others (Kementrian Kesehatan, 2016). According to Fitriana, (2016), Fine motor development is different from gross motor development which is identical with important achievements such as the ability to crawl, stand and walk which are easily observed, the results the research show that there is no statistically significant relationship between breastfeeding history and fine motor development with a p-value of 0.119 . In his research, $34.6 \%$ of the subjects had normal fine motor development even though they were not exclusively breastfed and $17.3 \%$ of the subjects were suspected of having developmental delays despite being exclusively breastfed.

The results of other studies show that babies who are exclusively breastfed have a chance of getting normal baby development according to age 2,500 times greater than babies who are not exclusively breastfed with $\mathrm{OR}=2,500$ and the chi-square test results get $\mathrm{p}$-value $=0.317$, which means there is no significant relationship between exclusive breastfeeding with the development of infants aged 6-12 months (Intani et al., 2019). Efforts to improve infant development are exclusive breastfeeding. Mother's Milk (ASI) is an environmental factor and nurturing need that contains the best nutrients for babies because breast milk contains all nutrients in ideal amounts and compositions and the nature of breast milk which is very easily absorbed by the baby's body is very useful to help optimal baby growth and development. and protects against various diseases (Intani et al., 2019). 
In this study, the researchers assumed that there was no relationship between breastfeeding and breastfeeding exclusive with the baby's fine motor skills because in addition to breastfeeding which can affect the child's growth and development, there are other factors such as the mother's ability to stimulate her baby, even though the baby is not exclusively breastfed but the baby gets good stimulation, the baby can also develop well according to his age. However, the best nutrition for babies is still exclusive breastfeeding for the first 6 months of life so that babies can develop optimally.

\section{CONCLUSION}

Distribution of the frequency of breastfeeding, as many as 33 respondents $(70.2 \%)$ who were given exclusive breastfeeding, and 14 respondents $(29.8 \%)$ who were not given exclusive breastfeeding.

The distribution of fine motor frequency, as many as 39 respondents $(83 \%)$ in the appropriate category, and as many as 7 respondents (14.9\%) in the doubtful category, and 1 respondent $(2.1 \%)$ experienced deviations.

There is no significant relationship between breastfeeding and fine motor skills in infants aged 6-12 months with a p-value of $0.058>0.05$.

\section{REFERENCES}

Azhari, A. (2019). The Relationship Between Exclusive and Non-Exclusive Breastfeeding and Gross Motor Development of Infants Age 6-12 Months In Posyandu, Working Area of Makam Haji Health Center. S1 Physiotherapy Study Program, Faculty of Health Sciences, University of Muhammadiyah Surakarta, 1-9.

Desitawati, H., Wattimena, I., \& Susanti, N. (2020). The Difference between the Gross Motoric and the Fine Motoric of Infants with An Exclusive And A Non-Exclusive Breast Feeding, Faculty of Immunology, Universitas Graduate School. Hospital Health Management Foundation. Dr. Soetomo, 6, 73-82.

Dinas Kesehatan Kota Palembang. (2020). Palembang City Health Office. Palembang City Health Profile 2020, 218.

Fitriana, IR (2016). Relationship between the history of breastfeeding and birth weight with gross motor development and fine motor development of infants aged 6-12 months. Research Article, Nutrition Science Study Program, Faculty of Medicine, Diponegoro University, 9-12.

Intani, TM, Syafrita, Y., \& Chundrayetti, E. (2019). The Relationship of Exclusive Breastfeeding and Psychosocial Stimulation with the Development of Infants Aged 6-12 Months. Andalas Health Journal, 8(1S), 7-13.

Karang, NNM, Winaya, IMN, Dinata, IMK, \& Nugraha, MHS (2020). The Relationship of Exclusive Breastfeeding with Growth and Development of Babies aged 0-12 Months at Puskesmas Ii, South Denpasar. Indonesian Physiotherapy Scientific Magazine, 8(2), 16. https://doi.org/10.24843/mifi.2020.v08.i02.p04 
Kemenkes, RI (2019). Give breast milk for optimal growth and development. https://www.kemkes.go.id/article/view/19080800004/gian-asi-untuk-tumuhkembang-optimal.html

Kementrian Kesehatan. (2016). Guidelines for the implementation of Stimulation, Detection, and Early Intervention of Child Development at the Primary Health Service Level.

Maria, M., Ina, AA, \& Windayani, W. (2020). The Relationship between Exclusive Breastfeeding and Non-Exclusive Breastfeeding with Fine Motor Development in Infants Age 6 Months. Journal of Nursing and Public Health, 8(1), 58-65.

Mualifah, L., \& Punjastuti, B. (2019). Monitoring Child Development With Etc. Karyan Husada Community Service Journal, 1(1), 24-29. http://jurnal.akeskhjogja.ac.id/index.php/jpmkh/article/view/175

Nurlaila, N., Kholifah, R., \& Ning, I. (2017). Relationship of exclusive breastfeeding with motor development in infants. Scientific Journal of Nursing Health, 13(2).

Tianingsih, N. (2020). The Effect of Exclusive Breastfeeding on Child Development Levels. http://eprintslib.ummgl.ac.id/id/eprint/2517

Yanti, D. (2017). Fine motor development in toddlers with exclusive breastfeeding is better than toddlers without exclusive breastfeeding. Health Research Shoots, VII(November), 285-287.

Zaid, R., Rusdi, R., \& Rismia, A. (2016). Exclusive Breastfeeding with the Development of 6 Months Old Babies in the Working Area of the Gunung Payung Health Center. Nursing World, 4, 65-69. 